\title{
Rhinitis Associated with Pesticide Use Among Private Pesticide Applicators in the Agricultural Health Study
}

\author{
Rebecca E. Slager, PhD ${ }^{1}$, Sean L. Simpson, $\mathrm{PhD}^{2}$, Tricia D. LeVan, PhD ${ }^{3}$, Jill A. Poole, \\ $\mathrm{MD}^{4}$, Dale P. Sandler, $\mathbf{P h D}^{5}$, and Jane A. Hoppin, $\mathbf{S c D}^{6}$ \\ Rebecca E. Slager: rslager@wfubmc.edu; Sean L. Simpson: slsimpso@wfubmc.edu; Tricia D. LeVan: tlevan@unmc.edu; \\ Jill A. Poole: japoole@unmc.edu; Dale P. Sandler: sandler@niehs.nih.gov; Jane A. Hoppin: hoppin1@niehs.nih.gov \\ ${ }^{1}$ Center for Genomics and Personalized Medicine Research, Wake Forest University School of \\ Medicine, Winston-Salem, NC, 27157 phone: 336-713-7513 \\ 2 Department of Biostatistics, Division of Public Health Sciences, Wake Forest University School of \\ Medicine, Winston-Salem, NC, 27157 phone: 336-716-8369 \\ 3 Pulmonary, Critical Care, Sleep, and Allergy Division, Department of Medicine and Department of \\ Epidemiology, College of Public Health, University of Nebraska Medical Center, Omaha, NE, 68198 \\ phone: 402-559-3985 \\ 4 Pulmonary, Critical Care, Sleep, and Allergy Division, Department of Medicine, University of \\ Nebraska Medical Center, Omaha NE, 68198 phone: (402) 559-6266 \\ ${ }^{5}$ Epidemiology Branch, National Institute of Environmental Health Sciences, Research Triangle \\ Park, NC 27709 phone: (919) 541-4668 \\ ${ }^{6}$ Epidemiology Branch, National Institute of Environmental Health Sciences, Research Triangle \\ Park, NC 27709 phone: (919) 541-7622
}

\begin{abstract}
Farmers commonly experience rhinitis but the risk factors are not well-characterized. The aim of this study was to analyze cross-sectional data on rhinitis in the past year and pesticide use from 21,958 Iowa and North Carolina farmers in the Agricultural Health Study, enrolled 1993-7, to evaluate pesticide predictors of rhinitis. Polytomous and logistic regression models were used to assess association between pesticide use and rhinitis while controlling for demographics and farm-related exposures. Sixty-seven \% of farmers reported current rhinitis and 39\% reported three or more rhinitis episodes. The herbicides glyphosate [Odds Ratio $(\mathrm{OR})=1.09,95 \%$ Confidence Interval $(95 \% \mathrm{CI})$ $=1.05-1.13]$ and petroleum oil $(\mathrm{OR}=1.12,95 \% \mathrm{CI}=1.05-1.19)$ were associated with current rhinitis and increased rhinitis episodes. Of the insecticides, 4 organophosphates (chlorpyrifos, diazinon, dichlorvos, and malathion), carbaryl and use of permethrin on animals were predictors of current rhinitis. Diazinon was significant in the overall polytomous model and was associated with an elevated $\mathrm{OR}$ of $13+$ rhinitis episodes $(13+$ episodes $\mathrm{OR}=1.23,95 \% \mathrm{CI}=1.09-1.38)$. The fungicide captan was also a significant predictor of rhinitis. Use of petroleum oil, malathion, permethrin and the herbicide metolachlor were significant in exposure-response polytomous models. Specific pesticides may contribute to rhinitis in farmers; agricultural activities did not explain these findings.
\end{abstract}

\footnotetext{
Address correspondence and reprint requests to: Jane A. Hoppin, ScD, Epidemiology Branch, NIEHS, P.O. Box 12233, MD A3-05, Research Triangle Park, NC, USA 27709, tel: (919) 541-7622, fax: (919) 541-2511, hoppin1@ niehs.nih.gov.

Disclosures: none

All authors contributed to this study and have no conflicts of interest to declare.
} 


\section{Key terms}

Nasal symptoms; occupational exposure; respiratory; rhinitis; pesticide

Rhinitis is a common chronic condition shown to have a substantial impact on the sufferer's ability to sleep, quality of life, cognitive function, and workplace productivity (Meltzer et al., 2009). Rhinitis is also linked to the development of asthma and worsening asthma severity (Slavin, 2008). Work in agricultural environments results in a substantial increased risk of developing several adverse respiratory health conditions including rhinitis, asthma, chronic bronchitis, and obstructive lung diseases. Exposures such as in large animal farming, growing grain and soybeans, and working in grain elevators have been associated with high rates of lower respiratory tract morbidity (Von Essen et al., 1990, 1999; Schwartz, 1996; Schenker, 1998; Von Essen and Donham, 1999; Sprince et al., 2000; Linaker and Smedley, 2002), but the potential risk factors for upper respiratory tract disease in this population are not well characterized. There are many potential causative factors, and combinations of multiple exposures in the agricultural environment are likely to be important. Activities such as livestock breeding and handling, dairy production, and grain farming have been associated with increased nasal symptoms (DoPico et al., 1977; Schenker, 1998; Monso et al., 2003). Swine barn dust was shown to induce nasal inflammation and symptoms in healthy volunteers (Ehnhage et al., 2007). Exposure to pesticides in agricultural work may also contribute to rhinitis, but few studies have examined this potential association.

Only two epidemiologic studies to date have focused on pesticide use and rhinitis (Chatzi et al., 2007; Slager et al., 2009). Grape farmers in Crete who used bipyridyl herbicides, dithiocarbamate fungicides, and carbamate insecticides had a higher prevalence of allergic rhinitis compared to grape farmers who did not apply these pesticides (Chatzi et al., 2007). A study of commercial pesticide applicators in the Agricultural Health Study (AHS) found that exposure to petroleum oil, the insecticide diazinon, the fungicide benomyl and use of both 2,4dichlorophenoxyacetic acid (2,4-D) and glyphosate were positively associated with current rhinitis (Slager et al., 2009). Petroleum oil has also been associated with wheeze in the AHS (Hoppin et al., 2002a, 2006). With large scale use of pesticides, understanding the potential association of pesticides and other farming exposures may lead to strategies for reducing morbidity from respiratory disease.

This analysis focused on the farmers of the large AHS private pesticide applicator cohort, which does not include the AHS commercial pesticide applicators, to evaluate the contribution of individual pesticides to rhinitis while controlling for the complex background of crop, animal, and farm maintenance exposures that contribute to nasal symptoms in farmers. A novel threestep modeling approach was employed to control for these potential confounders while maintaining model parsimony.

\section{MATERIALS AND METHODS}

\section{Study population}

The AHS is a prospective study of licensed pesticide applicators and spouses from Iowa and North Carolina (Alavanja et al., 1996). The cohort of 57,310 licensed pesticide applicators (52,394 private and 4,916 commercial applicators) was recruited between 1993 and 1997 from persons applying for certification to use restricted-use pesticides. Pesticide applicators were asked to complete two self-administered questionnaires, available at www.aghealth.org/questionnaires.html. All applicators completed the first questionnaire at enrollment; the second, more detailed take-home questionnaire was completed by $44 \%$ of the cohort. The second questionnaire contained information on rhinitis symptoms, while pesticide 
exposure information was collected on both surveys. This second questionnaire was completed by most participants within a month of enrollment. Thus, this analysis is restricted to the 22,916 private applicators who returned both the enrollment and take-home questionnaires. Though only $44 \%$ of farmers completed both questionnaires, demographic characteristics, farming and medical history are similar for responders and non-responders (Tarone et al., 1997). The Institutional Review Boards (IRB) of the National Institutes of Health (Bethesda, Maryland) and its contractors approved the AHS. At enrollment, the study was explained to potential participants, who indicated consent by returning questionnaires. The IRB at Wake Forest University School of Medicine approved this secondary analysis of AHS data.

\section{Outcome definition}

Respondents provided information on a number of allergic symptoms in the past year. The main outcome of current rhinitis was based on the applicator's response on the take-home questionnaire to the question: "during the past 12 months have you had a stuffy, itchy, or runny nose?" The number of rhinitis episodes was determined from the question "how many episodes of stuffy, itchy, or runny nose have you had in the past 12 months?" with possible responses: "1 episode, 2, episodes, 3-6 episodes, 7-12 episodes and more than 12 episodes."

\section{Exposure definition}

Pesticide exposure was assessed using both self-administered questionnaires. The first, completed at enrollment, obtained detailed information on use of 22 pesticides available at the time of enrollment (ever use, use during the past year, frequency of use and total number of years used) and information on use of 18 additional current use pesticides. The take-home questionnaire obtained more detailed information about the 18 additional pesticides. Applicators who reported use of a specific pesticide in the year before enrollment were considered current users. Information was available on the current use of 16 herbicides, 16 insecticides, 6 fungicides, and two fumigants. Applicators also provided information on agricultural exposures including 28 crops, 9 animal production exposures, and 14 farm maintenance activities, as well as demographic and medical information including smoking history.

\section{Statistical models}

The association between pesticide use in the past year and the number of episodes of rhinitis was examined using a three-step modeling approach. All three steps consisted of fitting a generalized logits model to the number of episodes of rhinitis in the past year $(1,2,3-6,7-12$ and 13+ episodes) compared to the reference category of no episodes of rhinitis in the past year. A proportional odds model was not employed due to the violation of model assumptions. In step 1, all potentially relevant demographic and general farming variables were included as predictors (Table 1): age, state of residence (Iowa or North Carolina), body mass index (BMI), gender, education, race, smoking status (current, former, or never smoker), growing up on a farm, currently live or work on a farm, and years applying pesticides. Age (centered), BMI (centered), years applying pesticides, and education were treated as continuous variables while the rest were treated as categorical. The model was then reduced via backward selection, leaving just the significant demographic covariates in the final model. A $p<0.05$ (two-sided) was regarded as statistically significant. In step 2 , two generalized logit models were fitted, one using relevant farming activities as predictors and the other using crop and animal exposures as predictors (Table 2). Both of these models were then reduced separately via backward selection, resulting in final models with just the significant covariates. The final step consisted of fitting 4 generalized logit models, one for each of the 4 pesticide categories: herbicides, insecticides, fumigants, and fungicides. Each model included as predictors: 1) the significant covariates from the first two steps and 2) all pesticides in the given category. This 
approach was taken in order to control for potential confounders while maintaining parsimony. These adjusted models not only control for potential confounding due to demographic and farm-related covariates, but also for correlated use of other pesticides within each category. To directly compare pesticides associated with any rhinitis and number of rhinitis episodes in the past year, a dichotomous logistic model was also developed to assess current/no current rhinitis with the same covariates as the final polytomous model.

Rhinitis may be a result of a cold or disease such as asthma. To assess whether our results were influenced by our definition of rhinitis, two subgroup analyses were conducted where individuals who had a cold in the past year or asthmatics were removed.

To model pesticide exposure-response in polytomous logistic models adjusted for the same demographic and farm-related exposures described above, continuous variables were included based on days applying pesticides in the past year, using categories from the questionnaire $(0$, $1-4,5-9,10-19,20-39,40-59,60-150$ days, more than 150 days). Each category was coded as the midpoint, for instance, the category 1-4 days of pesticides applied in the past year was encoded as 2.5 days. Herbicides and insecticides were modeled separately and exposureresponse was not assessed for fungicides, fumigants or the insecticide trichlorfon due to small numbers of exposed individuals.

All analyses were conducted using the P1REL0506 release of the AHS data with SAS software version 9.1 for Windows, SAS Institute Inc., Cary, NC.

\section{RESULTS}

Complete outcome information was available for 21,958 private pesticide (farmer) applicators. Farmers in the AHS are predominantly white (98\%) males (98\%). A total of 14,629 farmers $(67 \%)$ reported current rhinitis (Table 1). Farmers with rhinitis were younger, more educated, and more likely to be never smokers than those without rhinitis. There were no appreciable differences in gender or growing up on a farm between those with and without rhinitis. Individuals with rhinitis were also more likely to report asthma, conjunctivitis, and sinusitis symptoms. Of the AHS farmers who reported current rhinitis, the majority reported 3-6 episodes in the past year (35\%) and 15\% reported 13 or more episodes in the past year (Table 1). A polytomous model was fitted among applicators with completed data on all covariates $(n=19,565)$ to evaluate number of episodes of rhinitis. Age, state of residence, BMI, education, race, currently working on a farm, and years mixing pesticides were significant demographic predictors of rhinitis episodes and were included in subsequent models of farming and pesticide exposures.

The associations of farm-related activities with current rhinitis status were examined in logistic models as well as polytomous models. Two separate models were fit: one to evaluate farm activities (top portion of Table 2) and one to evaluate animal and crop exposures (bottom portion of Table 2). Table 2 presents the results of the dichotomous logistic models. Handling hay [Odds Ratio $(\mathrm{OR})=1.06,95 \%$ Confidence Interval $(95 \% \mathrm{CI})=1.02-1.10$ ] and working with swine $(\mathrm{OR}=1.05,95 \% \mathrm{CI}=1.01-1.09)$ were among several significant predictors of rhinitis. Individuals with rhinitis were also more likely to take part in maintenance activities such as repairing pesticide equipment $(\mathrm{OR}=1.16,95 \% \mathrm{CI}=1.12-1.20)$, and painting $(\mathrm{OR}=$ $1.15,95 \% \mathrm{CI}=1.11-1.19)$. The highest $\mathrm{OR}$ in dichotomous models for farm-related exposures was exposure to other farm animals $(\mathrm{OR}=1.25,95 \% \mathrm{CI}=1.12-1.41)$.

In the polytomous models, the significant predictors of rhinitis episodes retained in the final models to evaluate pesticides associated with rhinitis were: butchering animals, handling stored grain, handling stored hay, painting, repairing engines, repairing pesticide equipment, welding, working in swine areas, working with hogs and other farm animals, and growing cabbage, 
Christmas trees, field corn, sweet corn and hay. Repairing engines, handling stored grain, raising field corn and raising hay were only significant in the polytomous models.

Table 3 shows the frequency of use of herbicides and insecticides by rhinitis status. The herbicides glyphosate and petroleum oil and the insecticides diazinon, malathion, carbofuran, and permethrin on animals were significantly associated with rhinitis in the polytomous models (global $p<0.05$ ) (Table 4). In the dichotomous model, the herbicides glyphosate ( $\mathrm{OR}=1.09$, $95 \% \mathrm{CI}=1.05-1.13)$ and petroleum oil $(\mathrm{OR}=1.12,95 \% \mathrm{CI}=1.05-1.19)$ were significantly associated with current rhinitis. Six of the 16 insecticides analyzed were also associated with rhinitis in the dichotomous logistic model (data not shown), including dichlorvos, which had the highest $\mathrm{OR}(\mathrm{OR}=1.15,95 \% \mathrm{CI}=1.03-1.28)$, and other organophosphates including chlorpyrifos $(\mathrm{OR}=1.06,95 \% \mathrm{CI}=1.01-1.11)$, diazinon $(\mathrm{OR}=1.12,95 \% \mathrm{CI}=1.03-1.21)$, and malathion $(\mathrm{OR}=1.06,95 \% \mathrm{CI}=1.01-1.11)$. For most pesticides, there was no discernible pattern of association with number of rhinitis episodes, though use of the herbicides glyphosate and petroleum oil and the insecticide permethrin on animals were consistently associated with increased number of episodes (Table 4). Six herbicides and insecticides were significantly and positively associated with 13 or more episodes of rhinitis in the past year (data not shown), including petroleum oil $(13+$ episodes $\mathrm{OR}=1.23,95 \% \mathrm{CI}=1.11-1.35)$ and lindane $(13+$ episodesOR $=1.26,95 \% \mathrm{CI}=1.03-1.55$ ), which had the highest $\mathrm{OR}$. Use of carbofuran was inversely associated with rhinitis episodes in the polytomous model and, to a lesser extent, inversely associated with any rhinitis in the dichotomous model (Table 4).

Adjusted polytomous models were also developed to assess 6 fungicides and two fumigant predictors of rhinitis episodes (data not shown). Only the fungicide captan was significantly associated with increased number of rhinitis episodes (global $p<0.0001$ ). The strongest association between captan use and rhinitis was noted for 7-12 episodes in past year (7-12 episodes $\mathrm{OR}=1.32,95 \% \mathrm{CI}=1.17-1.49)$. Fumigant use was not associated with rhinitis episodes (data not shown).

Exposure-response polytomous models were developed to assess whether increased days applying pesticides were associated with increased episodes of rhinitis. Of the herbicides and insecticides associated with rhinitis (Table 4), only the herbicide petroleum oil $(p=0.02)$ and use of permethrin on animals $(p=0.03$ ) had significant, positive exposure-response association with rhinitis episodes (data not shown). Carbofuran had a borderline inverse association with rhinitis $(p=0.06)$ in exposure-response models. The herbicide metolachlor, which was not statistically associated with rhinitis in ever use models (data not shown), was significant in the exposure-response model $(p=0.03)$.

Other exploratory subgroup analysis in the herbicide and insecticide models investigated whether reported medical conditions such as asthma or colds attenuated our results. When individuals with asthma (7\% of individuals with rhinitis and 3\% of controls) were excluded, essentially the same pesticides associations were observed except that the estimate for carbaryl became statistically significant (data not shown). When participants with colds in the past year were excluded from models ( $\mathrm{n}=17,260,79 \%$ of farmers), glyphosate and malathion remained significantly associated with rhinitis. Carbaryl and 2,4-D were significant predictors of rhinitis episodes in these models but not in those with the broader case definition (data not shown). However, our ability to detect associations in these models was reduced due to the high prevalence of colds.

\section{DISCUSSION}

Pesticide use may play a role in rhinitis in Agricultural Health Study farmers. Conservative logistic and generalized logits models were constructed with the same covariates to assess 
pesticides associated with any rhinitis (dichotomous) and number of rhinitis episodes (polytomous). This approach is novel as few studies have the power to assess individual pesticides associated with rhinitis episodes after controlling for potential confounders. A threestep modeling strategy was developed to adjust for: 1) significant demographic characteristics which may differ between individuals with and without rhinitis, 2) significant farm-related predictors of rhinitis, and 3) correlated use within the pesticide classes (herbicides, insecticides, fungicides, and fumigants). There was little correlation $(r<0.2)$ between different classes of pesticides, suggesting, for instance, that herbicides would be unlikely to confound insecticide associations. When the results of the dichotomous and polytomous modeling strategies were compared, the herbicides glyphosate and petroleum oil were significant in both models; petroleum oil was also significant in exposure-response models. Most insecticide predictors of current rhinitis were statistically associated with increased number of episodes based on the global $p<0.05$ for the polytomous model; however, only use of permethrin on animals was consistently associated with multiple categories of rhinitis episodes. Of these significant pesticides, glyphosate, petroleum oil, carbaryl, diazinon, and permethrin were also predictors of 13 or more rhinitis episodes in the past year, suggesting that these pesticides may contribute to increased nasal symptoms, independent of other farm-related exposures.

Similar to previous reports, farming exposures such as handling grain and hay and working with swine were associated with increased nasal symptoms (Von Essen et al., 1990; Andersen et al., 2004). Some of the strongest farm-related associations with rhinitis in the AHS were with maintenance activities such as welding, painting, and repairing engines and pesticide equipment. Though there is limited information on farm maintenance activities and nasal symptoms, chemical exposure to paints, epoxies, and resins is known to produce nasal irritation (Drake-Lee et al., 2002). However, the pesticide associations with rhinitis in the AHS farmers observed here were independent of these other crop, animal or farm maintenance exposures. The observed ORs for nasal symptoms were small, consistent with other studies of symptoms (Hoppin et al., 2002a), probably due to the low degree of specificity of these symptoms. While the ORs were small, they were statistically significant and there was evidence of increasing rhinitis with increasing usage of specific chemicals.

Some pesticides included in this analysis have been reported to play a role in respiratory conditions, though few have been specifically evaluated for nasal symptoms. Petroleum oil herbicide has consistently been associated with upper and lower respiratory symptoms in the AHS. In commercial applicators, petroleum oil was significantly associated with increased odds of rhinitis (Slager et al., 2009). Petroleum oil has also been associated with wheeze in commercial and private pesticide applicators in the AHS (Hoppin et al., 2002a, 2006).

Glyphosate, which was a significant predictor of rhinitis episodes in this study, was previously associated with increased allergic rhinitis in grape farmers in Crete (Chatzi et al., 2007). In commercial applicators in the AHS, use of glyphosate was highly correlated with 2,4-D $(r=$ 0.7 ) and rhinitis increased only with use of both chemicals in the past year. Use of glyphosate and 2,4-D by private pesticide applicators in the AHS was not as highly correlated $(r=0.4)$ and there was no association for use of these chemicals in combination. There is also evidence for a role of organophosphate insecticides in respiratory symptoms. Several organophosphates were associated with rhinitis in this analysis, some of which were predictors of wheeze in AHS farmers or commercial applicators (Hoppin et al., 2002a, 2006). Diazinon was also associated with rhinitis in AHS commercial pesticide applicators (Slager et al., 2009). In addition, consistent with the findings for commercial applicators was the inverse association observed with carbofuran, a carbamate insecticide, and rhinitis.

There is limited information on the mechanisms of pesticide-induced upper respiratory symptoms. There have been recent studies suggesting pesticide exposure may be associated with serum markers of cytotoxicity (Hernandez et al., 2006). Specifically, studies demonstrate 
that glyphosate can inhibit the in vitro activity of several metabolic enzymes including acetyl cholinesterase (El-Demerdash et al., 2001). Furthermore, adjuvants in the commercially available Roundup ${ }^{\circledR}$ formulations may enhance or amplify glyphosate toxicity in umbilical, embryonic and placental cells (Benachour and Seralini, 2009). However, these bioindicator assays do not provide a clear link to respiratory morbidity or systemic health effects.

This analysis relied on self-reported rhinitis in the past year and the case definition did not exclude those with upper respiratory infections, therefore, our estimate of rhinitis prevalence is high (67\%). Farmers or farm residents in New York reported a comparable prevalence (57\%) and similar demographic risk factors for stuffy nose/watery eye symptoms (Gomez et al., 2004). In these New York farmers, pesticide and fertilizer spraying in the past year was a significant predictor of stuffy nose/watery symptoms. Rhinitis was also commonly reported among greenhouse flower and ornamental plant growers in Europe (31\%) and was related to hand pump pesticide application (Riu et al., 2008). Several other studies have assessed rhinitis, but the outcome measures have not been consistent, especially in occupational research (Moscato et al., 2008), and it is difficult to directly compare prevalence estimates. The rhinitis prevalence in AHS farmers (67\%) was two to three times higher than US and European prevalence estimates (20-30\%) (Nathan, 2007; Radon et al., 2008) and higher than Cretean grape farmers (51\%) (Chatzi et al., 2007). A limitation of this analysis is that there was no information on allergen sensitivity such as skin prick positivity or serum IgE levels and therefore it was not possible to distinguish between allergic and non-allergic rhinitis. However, when participants who reported asthma were excluded, the pesticide findings were similar. To assess whether the findings may be influenced by rhinitis due to colds, an analysis was conducted where $79 \%$ of participants were excluded who reported colds in the past year. In this reduced analysis, some similar results were seen, but the power to detect associations was limited.

This analysis is restricted to the $44 \%$ of AHS private pesticide applicators who responded to both enrollment and take-home questionnaires. Previous studies showed demographic characteristics, farming and medical history to be similar between those who did and did not return the take-home questionnaire (Tarone et al., 1997). However, it was not possible to assess differences in rhinitis between responders and non-responders as the question regarding nasal symptoms was asked only on the take-home survey. Recall bias related to rhinitis episodes and pesticide exposure is possible though unlikely due to the wide range of health outcomes and exposures assessed in the questionnaire. Furthermore, it was also not possible to establish a temporal relationship between pesticide exposure and rhinitis in this cross-sectional analysis.

The major strength of this study is the large sample size and detailed data that together provide the ability to evaluate individual pesticides while controlling for background agricultural exposures. Pesticide exposure variables from the AHS were found to be reliable and reproducible in farmers (Blair and Zahm, 1993; Hoppin et al., 2002b). Moreover, there are few reports of occupational exposures associated with rhinitis episodes and a limited number of studies have the ability to estimate the effect of individual pesticides on increased nasal symptoms. Rhinitis is an independent risk factor for the development of asthma and is associated with exacerbations and worsening of asthma disease (Guerra et al., 2002; Slavin, 2008; Cirillo et al., 2009; Meltzer et al., 2009). Farmers were found to be at high risk for asthma related to occupational rhinitis (Karjalainen et al., 2003). Studies such as this are important for understanding occupational risk factors for rhinitis in order to reduce respiratory morbidity in agricultural workers.

Pesticide exposure may play a role in nasal symptoms in farmers independent of handling hay and grain, working with farm animals, and maintenance activities such as welding and painting. Though limited by cross-sectional study design and a broad definition of rhinitis, this analysis 
took advantage of a large sample size and reliable exposure information to evaluate herbicides and insecticides associated with rhinitis. These results suggest that exposure to organophosphate insecticides may increase the odds of rhinitis and that exposure to the herbicides glyphosate and petroleum oil may contribute to multiple rhinitis episodes.

\section{Acknowledgments}

This work is supported by intramural research funds (for the AHS) from the National Institute of Environmental Health Sciences (Z01-ES049030) and the National Cancer Institute (Z01-CP010119), National Institutes of Health, US Department of Health and Human Services. RES is supported by the National Institutes of Health and National Heart, Lung, and Blood Institute K12 Scholars' Program in the Genetics and Genomics of Lung Disease, Principal Investigator Deborah A. Meyers, PhD (K12 HL89992) at the Wake Forest University School of Medicine.

We would like to thank Stuart Long for preparation of the AHS dataset.

\section{Abbreviations}

$\begin{array}{ll}\text { 2,4-D } & \text { 2,4-dichlorophenoxyacetic acid } \\ \text { EPTC } & \text { S-ethyl dipropylthiocarbamate } \\ \text { AHS } & \text { Agricultural Heath Study } \\ \text { BMI } & \text { Body mass index } \\ \text { CI } & \text { Confidence Interval } \\ \text { IRB } & \text { Institutional Review Board } \\ \text { OR } & \text { Odds Ratio }\end{array}$

\section{References}

Alavanja MC, Sandler DP, McMaster SB, Zahm SH, McDonnell CJ, Lynch CF, Pennybacker M, Rothman N, Dosemeci M, Bond AE, Blair A. The Agricultural Health Study. Environ Health Persp 1996;104:362-369.

Andersen CI, Von Essen SG, Smith LM, Spencer J, Jolie R, Donham KJ. Respiratory symptoms and airway obstruction in swine veterinarians: a persistent problem. Am J Ind Med 2004;46:386-392. [PubMed: 15376211]

Benachour N, Seralini GE. Glyphosate formulations induce apoptosis and necrosis in human umbilical, embryonic, and placental cells. Chem Res Toxicol 2009;22:97-105. [PubMed: 19105591]

Blair A, Zahm SH. Patterns of pesticide use among farmers: implications for epidemiologic research. Epidemiology 1993;4:55-62. [PubMed: 8420582]

Chatzi L, Alegakis A, Tzanakis N, Siafakas N, Kogevinas M, Lionis C. Association of allergic rhinitis with pesticide use among grape farmers in Crete, Greece. Occup Environ Med 2007;64:417-421. [PubMed: 17182637]

Cirillo I, Pistorio A, Tosca M, Ciprandi G. Impact of allergic rhinitis on asthma: effects on bronchial hyperreactivity. Allergy 2009;64:439-444. [PubMed: 19175597]

DoPico GA, Reddan W, Flaherty D, Tsiatis A, Peters ME, Rao P, Rankin J. Respiratory abnormalities among grain handlers: a clinical, physiologic, and immunologic study. Am Rev Respir Dis 1977;115:915-927. [PubMed: 262104]

Drake-Lee A, Ruckley R, Parker A. Occupational rhinitis: a poorly diagnosed condition. J Laryngol Otol 2002;116:580-585. [PubMed: 12389682]

Ehnhage A, Kolbeck KG, Juto JE, Grudemo H, Stjarne P. Swine dust exposure is a model for rapid induction of non-allergic neutrophil inflammation in the nasal mucosa of healthy volunteers, and the symptoms as well as the microcirculation are modified by nasal lavage. Rhinology 2007;45:292-298. [PubMed: 18085023] 
El-Demerdash FM, Yousef MI, Elagamy EI. Influence of paraquat, glyphosate, and cadmium on the activity of some serum enzymes and protein electrophoretic behavior (in vitro). J Environ Sci Health B 2001;36:29-42. [PubMed: 11281253]

Gomez MI, Hwang SA, Lin S, Stark AD, May JJ, Hallman EM. Prevalence and predictors of respiratory symptoms among New York farmers and farm residents. Am J Ind Med 2004;46:42-54. [PubMed: 15202124]

Guerra S, Sherrill DL, Martinez FD, Barbee RA. Rhinitis as an independent risk factor for adult-onset asthma. J Allergy Clin Immunol 2002;109:419-425. [PubMed: 11897985]

Hernandez AF, Amparo Gomez M, Perez V, Garcia-Lario JV, Pena G, Gil F, Lopez O, Rodrigo L, Pino $\mathrm{G}$, Pla A. Influence of exposure to pesticides on serum components and enzyme activities of cytotoxicity among intensive agriculture farmers. Environ Res 2006;102:70-76. [PubMed: 16620808]

Hoppin JA, Umbach DM, London SJ, Alavanja MC, Sandler DP. Chemical predictors of wheeze among farmer pesticide applicators in the Agricultural Health Study. Am J Respir Crit Care Med 2002a; 165:683-689. [PubMed: 11874814]

Hoppin JA, Umbach DM, London SJ, Lynch CF, Alavanja MC, Sandler DP. Pesticides associated with wheeze among commercial pesticide applicators in the Agricultural Health Study. Am J Epidemiol 2006;163:1129-1137. [PubMed: 16611668]

Hoppin JA, Yucel F, Dosemeci M, Sandler DP. Accuracy of self-reported pesticide use duration information from licensed pesticide applicators in the Agricultural Health Study. J Expo Anal Environ Epidemiol 2002b;12:313-318. [PubMed: 12198579]

Karjalainen A, Martikainen R, Klaukka T, Saarinen K, Uitti J. Risk of asthma among Finnish patients with occupational rhinitis. Chest 2003;123:283-288. [PubMed: 12527633]

Linaker C, Smedley J. Respiratory illness in agricultural workers. Occup Med (Lond) 2002;52:451-459. [PubMed: 12488515]

Meltzer EO, Nathan R, Derebery J, Stang PE, Campbell UB, Yeh WS, Corrao M, Stanford R. Sleep, quality of life, and productivity impact of nasal symptoms in the United States: findings from the Burden of Rhinitis in America survey. Allergy Asthma Proc 2009;30:244-254. [PubMed: 19549425]

Monso E, Schenker M, Radon K, Riu E, Magarolas R, McCurdy S, Danuser B, Iversen M, Saiki C, Nowak D. Region-related risk factors for respiratory symptoms in European and Californian farmers. Eur Respir J 2003;21:323-331. [PubMed: 12608449]

Moscato G, Vandenplas O, Gerth Van Wijk R, Malo JL, Quirce S, Walusiak J, Castano R, De Groot H, Folletti I, Gautrin D, Yacoub MR, Perfetti L, Siracusa A. Occupational rhinitis. Allergy 2008;63:969980. [PubMed: 18691299]

Nathan RA. The burden of allergic rhinitis. Allergy Asthma Proc 2007;28:3-9. [PubMed: 17390749]

Radon K, Gerhardinger U, Schulze A, Zock JP, Norback D, Toren K, Jarvis D, Held L, Heinrich J, Leynaert B, Nowak D, Kogevinas M. Occupation and adult onset of rhinitis in the general population. Occup Environ Med 2008;65:38-43. [PubMed: 17664253]

Riu E, Monso E, Marin A, Magarolas R, Radon K, Morera J, Andreo F, Nowak D. Occupational risk factors for rhinitis in greenhouse flower and ornamental plant growers. Am J Rhinol 2008;22:361364. [PubMed: 18702898]

Schenker, MB., editor. Am J Respir Crit Care Med. Vol. 158. 1998. Respiratory health hazards in agriculture; p. S1-S76.

Schwartz DA. Grain dust, endotoxin, and airflow obstruction. Chest 1996;109:57S-63S. [PubMed: 8598158]

Slager RE, Poole JA, LeVan TD, Sandler DP, Alavanja MC, Hoppin JA. Rhinitis associated with pesticide exposure among commercial pesticide applicators in the Agricultural Health Study. Occup Environ Med 2009;66:718-724. [PubMed: 19289390]

Slavin RG. The upper and lower airways: the epidemiological and pathophysiological connection. Allergy Asthma Proc 2008;29:553-556. [PubMed: 19173781]

Sprince NL, Lewis MQ, Whitten PS, Reynolds SJ, Zwerling C. Respiratory symptoms: associations with pesticides, silos, and animal confinement in the Iowa Farm Family Health and Hazard Surveillance Project. Am J Ind Med 2000;38:455-462. [PubMed: 10982987] 
Tarone RE, Alavanja MC, Zahm SH, Lubin JH, Sandler DP, McMaster SB, Rothman N, Blair A. The Agricultural Health Study: factors affecting completion and return of self-administered questionnaires in a large prospective cohort study of pesticide applicators. Am J Ind Med 1997;31:233-242. [PubMed: 9028440]

Von Essen S, Donham K. Illness and injury in animal confinement workers. Occup Med 1999;14:337350. [PubMed: 10329909]

Von Essen S, Fryzek J, Nowakowski B, Wampler M. Respiratory symptoms and farming practices in farmers associated with an acute febrile illness after organic dust exposure. Chest 1999;116:14521458. [PubMed: 10559111]

Von Essen SG, Thompson AB, Robbins RA, Jones KK, Dobry CA, Rennard SI. Lower respiratory tract inflammation in grain farmers. Am J Ind Med 1990;17:75-76. [PubMed: 2305797] 
Table 1

Characteristics of 21,958 Agricultural Health Study Farmers by Rhinitis Status, Enrolled 1993-7.

\begin{tabular}{|c|c|c|c|c|}
\hline & \multicolumn{2}{|c|}{ Current rhinitis $^{a}$ n=14,629 } & \multicolumn{2}{|c|}{ No current rhinitis $n=7,329$} \\
\hline & No. & $\%$ & No. & $\%$ \\
\hline \multicolumn{5}{|l|}{ Age } \\
\hline $14-30$ & 1,372 & 9 & 316 & 4 \\
\hline $31-40$ & 3,775 & 26 & 987 & 14 \\
\hline $41-50$ & 3,866 & 26 & 1,699 & 23 \\
\hline $51-60$ & 2,953 & 20 & 2,107 & 29 \\
\hline $61-92$ & 2,663 & 18 & 2,220 & 30 \\
\hline \multicolumn{5}{|l|}{ State } \\
\hline Iowa & 9,778 & 67 & 4,609 & 63 \\
\hline North Carolina & 4,851 & 33 & 2,720 & 37 \\
\hline \multicolumn{5}{|l|}{ Body mass index $\left(\mathrm{kg} / \mathrm{m}^{2}\right)$} \\
\hline$<25$ & 3,911 & 27 & 1,854 & 25 \\
\hline$\geq 25$ & 10,718 & 73 & 5,475 & 75 \\
\hline \multicolumn{5}{|l|}{ Gender } \\
\hline Male & 14,248 & 97 & 7,178 & 98 \\
\hline Female & 381 & 3 & 151 & 2 \\
\hline \multicolumn{5}{|l|}{ Education level } \\
\hline$\leq$ High school & 7,543 & 54 & 4,428 & 64 \\
\hline >High school & 6,467 & 46 & 2,520 & 36 \\
\hline \multicolumn{5}{|l|}{ Race } \\
\hline White & 14,075 & 99 & 6,921 & 98 \\
\hline Other & 203 & 1 & 158 & 2 \\
\hline Conjunctivitis $b$ & 7,285 & 52 & 396 & 5 \\
\hline Sinusitis $c$ & 6,405 & 45 & 1,049 & 15 \\
\hline Asthma $d$ & 949 & 7 & 218 & 3 \\
\hline Colds $e^{e}$ & 13,076 & 91 & 4,184 & 57 \\
\hline \multicolumn{5}{|l|}{ Episodes of rhinitis past year } \\
\hline 0 & 0 & 0 & 7,329 & 100 \\
\hline 1 & 1,650 & 12 & . & . \\
\hline 2 & 4,179 & 29 & . & . \\
\hline $3-6$ & 4,998 & 35 & . & . \\
\hline $7-12$ & 1,349 & 9 & . & . \\
\hline$>12$ & 2,140 & 15 & . & . \\
\hline \multicolumn{5}{|l|}{ Smoking status } \\
\hline Never smoker & 7,942 & 56 & 3,593 & 51 \\
\hline Past smoker & 4,444 & 31 & 2,494 & 36 \\
\hline Current smoker & 1,818 & 13 & 931 & 13 \\
\hline Grew up on a farm $f$ & 13,312 & 91 & 6,734 & 92 \\
\hline Currently own or work on a farm & 13,670 & 97 & 6,734 & 96 \\
\hline
\end{tabular}




\begin{tabular}{lllll}
\hline & \multicolumn{2}{l}{ Current rhinitis $^{a}$ n=14,629 } & \multicolumn{2}{l}{ No current rhinitis $\mathbf{n = 7 , 3 2 9}$} \\
& No. & \% & No. & \% \\
\hline Years applying pesticides & & & & \\
None & 85 & 1 & 46 & 1 \\
$\leq 1$ & 261 & 2 & 125 & 2 \\
$2-5$ & 1,447 & 11 & 646 & 10 \\
$6-10$ & 2,030 & 15 & 897 & 13 \\
$11-20$ & 4,692 & 34 & 1,955 & 29 \\
$21-30$ & 3,354 & 24 & 1,807 & 27 \\
$>30$ & 1,935 & 14 & 1,255 & 19 \\
\hline
\end{tabular}

${ }^{a}$ Current rhinitis defined as yes to "during the past 12 months have you had a stuffy, itchy, or runny nose?"

${ }^{b}$ Conjunctivitis defined as yes to "during the past 12 months have you had a watery, itchy eyes?"

${ }^{c}$ Sinusitis defined as yes to "during the past 12 months have you had sinusitis or sinus problems?"

$d$ Asthma defined as yes to "ever diagnosed with asthma?"

${ }^{e}$ Colds defined as yes to "during the past 12 months have you had a cold?"

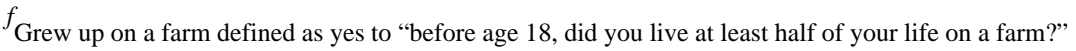




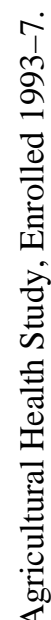


Table 3

Herbicide and Insecticide Use in the Past Year by Rhinitis Status Among 21,958 Private Pesticide Applicators in the Agricultural Health Study, Enrolled 1993-7.

\begin{tabular}{|c|c|c|c|c|}
\hline \multirow[b]{2}{*}{ Chemical } & \multicolumn{2}{|c|}{ Current rhinitis $n=14,629$} & \multicolumn{2}{|c|}{ No current rhinitis $n=7,329$} \\
\hline & No. & $\%$ exposed & No. & $\%$ exposed \\
\hline \multicolumn{5}{|l|}{ Herbicides } \\
\hline $2,4-\mathrm{D}$ & 5,277 & 36 & 2,158 & 29 \\
\hline Alachlor & 1,350 & 9 & 549 & 8 \\
\hline Atrazine & 4,397 & 30 & 1,800 & 25 \\
\hline Butylate & 145 & 1 & 58 & 1 \\
\hline Chlorimuron-ethyl & 1,760 & 12 & 741 & 10 \\
\hline Cyanazine & 1,473 & 10 & 543 & 7 \\
\hline Dicamba & 3,045 & 21 & 1,184 & 16 \\
\hline EPTC & 381 & 3 & 164 & 2 \\
\hline Glyphosate & 6,207 & 42 & 2,500 & 34 \\
\hline Imazethapyr & 4,030 & 28 & 1,697 & 23 \\
\hline Metolachlor & 2,660 & 18 & 1,094 & 15 \\
\hline Metribuzin & 626 & 4 & 278 & 4 \\
\hline Paraquat & 502 & 3 & 237 & 3 \\
\hline Pendamethalin & 1,929 & 13 & 847 & 12 \\
\hline Petroleum oil & 1,127 & 8 & 375 & 5 \\
\hline Trifluralin & 2,437 & 17 & 1,018 & 14 \\
\hline \multicolumn{5}{|l|}{ Insecticides } \\
\hline \multicolumn{5}{|l|}{ Organophosphates } \\
\hline Chlorpyrifos & 2,397 & 16 & 921 & 13 \\
\hline Coumaphos & 419 & 3 & 156 & 2 \\
\hline Diazinon & 874 & 6 & 315 & 4 \\
\hline Dichlorvos & 410 & 3 & 112 & 2 \\
\hline Fonofos & 591 & 4 & 250 & 3 \\
\hline Malathion & 2,529 & 17 & 995 & 14 \\
\hline Parathion & 139 & 1 & 51 & 1 \\
\hline Phorate & 365 & 3 & 169 & 2 \\
\hline Terbufos & 1,626 & 11 & 700 & 10 \\
\hline Trichlorfon & 17 & 0.1 & 4 & 0.1 \\
\hline \multicolumn{5}{|l|}{ Carbamates } \\
\hline Aldicarb & 460 & 3 & 207 & 3 \\
\hline Carbaryl & 1,821 & 12 & 804 & 11 \\
\hline Carbofuran & 307 & 2 & 150 & 2 \\
\hline \multicolumn{5}{|l|}{ Other } \\
\hline Lindane & 207 & 1 & 69 & 1 \\
\hline Permethrin on crops & 666 & 5 & 253 & 4 \\
\hline Permethrin on animals & 721 & 5 & 198 & 3 \\
\hline
\end{tabular}

J Toxicol Environ Health A. Author manuscript; available in PMC 2010 October 27. 


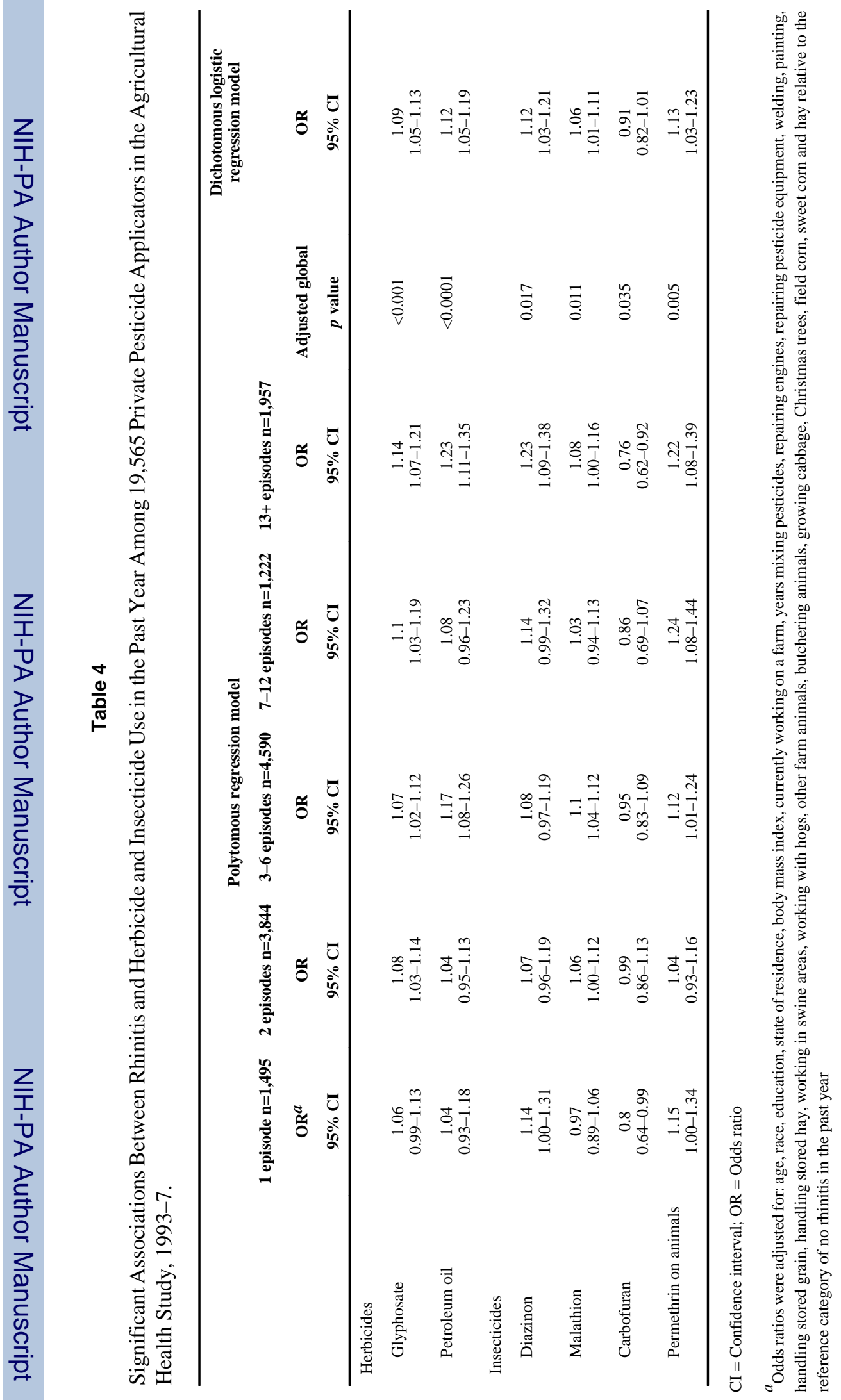

